\title{
Primary sclerosing cholangitis in children and adolescents: a clinicopathologic study with a proposal of criteria for early diagnosis
}

\author{
Colangite esclerosante primária em crianças e adolescentes: uma correlação clinicopatológica com uma proposta \\ de critérios para primeiro diagnóstico
}

Wolfram F. J. Riedlinger'; Maureen M. Jonas² ; Harpreet Pall ${ }^{3}$

key words
$\begin{aligned} & \text { Primary sclerosing } \\ & \text { cholangitis }\end{aligned}$
Liver
Neutrophilic
pericholangitis
Cholangiography
Inflammatory bowel
disease

\section{abstract}

Introduction: Primary sclerosing cholangitis (PSC) has been increasingly diagnosed among children and adolescents due to better recognition of clinical, imaging and pathological features. Thus more patients are diagnosed at a younger age due to imaging and sensitivity optimization. Objective: Early liver histopathological (LH) changes are not well described and PSC is not commonly recognized before typical bile duct changes occur on cholangiography (CG). Currently, CG is considered gold standard for adults but nothing is known for early diagnosis in the pediatric age group (0-20 years old). Methods: We reviewed clinical history, LH and CG from 47 children and adolescents with PSC ( 35 males, mean age 13 years old). Forty-three out of 47 patients had been through LH examination from whom 33 had also undergone CG. A clinicopathological correlation was performed. Results: LH showed active neutrophilic cholangitis in 19 patients, moderate neutrophilic pericholangitis in nine, dystrophic changes in the bile duct in eight, and concentric periductal fibrosis in 24 patients. Abnormal CG was found in 24 out of 33 patients and nine had normal results. Eleven out of these 24 patients had abnormal histology before abnormal CG and four patients had abnormal CG before histology. Data of two out of 24 patients were insufficient for correlation and 11 out of 24 had both abnormal liver histology and abnormal imaging findings. Conclusion: Our study emphasizes that even when CG is normal, PSC should be exclusively diagnosed by liver biopsy, hence cholangiography being unnecessary. Chronic portal inflammation, neutrophilic pericholangitis, periductal sclerosis and "onion skinning" are characteristic histopathological findings. Neutrophilic pericholangitis may be subtle and easily overlooked in early disease, leading to strong suspicion of PSC.

\section{resumo}

Introdução: Colangite esclerosante primária (CEP) é crescentemente diagnosticada em crianças e adolescentes devido ao melhor reconhecimento das apresentações clínicas por imagem e manifestações patológicas. Devido a isso, aumentaram a sensibilização e a melhora das imagens e, cada vez mais, os pacientes são diagnosticados em idade mais jovem. Objetivo: As primeiras mudanças na histopatologia do fígado (HF) não são bem descritas e a CEP não é frequentemente reconhecida antes da típica mudança do ducto biliar ocorrer na colangiografia (CG). Atualmente, a CG é considerada padrão-ouro em adultos, mas nada é conhecido para o diagnóstico precoce na faixa etária pediátrica (0-20 anos de idade). Métodos: Nós revisamos histórico clínico, HF e CG de 47 crianças e adolescentes com CEP (35 meninos, idade média de 13 anos). Desses, 43 tinham $H F$, sendo que 33 também possuíam CG. Uma correlação clinicopatológica foi performada. Resultados: HF mostrou colangite neutrofilica a tiva em 19 pacientes, pericolangite neutrofilica moderada em nove, mudança distrófica do ducto biliar em oito e fibrose periductal concêntrica em 24. Um CG anormal foi constatado em 24/33; resultados de nove pacientes eram normais. Desses 24 pacientes, 11 tiveram histologia anormal de fígado antes da CG anormal e quatro apresentaram a situação inversa. Dados disponíveis de dois pacientes eram insuficientes para propósitos de correlação e outros 11 apresentavam, ao mesmo tempo, histologia anormal de fígado e resultados anormais de imagens. Conclusão: Nosso estudo enfatiza que a CEP pode ser exclusivamente diagnosticada por biópsia de fígado, sem colangiograma necessário ou mesmo no contexto de um CG normal. Inflamação portal crônica, pericolangite neutrofílica, esclerose periductal e "cebola esfolando" são resultados característicos de achados histopatológicos. A pericolangite neutrofílica pode ser sutil e facilmente negligenciada em doença precoce, requerendo alta suspeita para CEP.

\section{unitermos}

Colangite esclerosante primária

Fígado

Pericolangite neutrofilica

Colangiografia

Doença inflamatória do intestino

1. Dr. med. (CER), MD (ECFMG, USA); Consultant Histopathologist, Department of Pathology, Aberdeen University Medical School, Aberdeen Royal Infirmary, Foresterhill, Aberdeen, Scotland, United Kingdom; formerly: Department of Pathology, Boston Children's Hospital, Harvard Medical School, Boston, USA.

2. MD (USA); Associate in Medicine \& Associate Professor of Pediatrics; Consultant Castroenterologist/Nutritionist, Boston Children's Hospital, Harvard Medical School, Boston, USA. 3. MD (USA); Instructor in Pediatrics; Director of Castrointestinal Satellite Endoscopy Program; Consultant Gastroenterologist/Nutritionist, Boston Children's Hospital, Harvard Medical School, Boston, USA. 


\section{Introduction}

Primary sclerosing cholangitis (PSC) manifests itself as a rare cholestatic liver disease of unclear etiology ${ }^{(23)}$. Typical histology reveals a mixed chronic inflammatory infiltrate within portal tracts, around and within bile duct walls, and a progressive, obliterative, concentric, periductal fibrosis affecting both the intra and extrahepatic bile ducts ${ }^{(3,24)}$. Especially, the periductal concentric ("onion-skinning") fibrosis of the small intrahepatic bile ducts has long been considered the histologic hallmark of the disease ${ }^{(4)}$.

No effective medical therapy has been proven to prevent disease progression. Therefore, affected patients may progress to biliary cirrhosis and liver failure consecutively making in liver transplantation the only life-extending therapeutic option for patients with end-stage disease ${ }^{(2,15)}$. However, a close to $25 \%$ recurrence rate in the allograft has been reported ${ }^{(12)}$.

Most patients with PSC present with rather unspecific signs and symptoms of chronic liver disease such as hepatosplenomegaly, abdominal pain, anorexia, fatigue, jaundice, pruritus, and cirrhosis ${ }^{(28)}$. PSC has also been described in the neonatal period when patients often present with cholestasis ${ }^{(8)}$.

Unfortunately, the underlying pathologic process is often not recognized on liver biopsy specimen before typical bile duct changes are evident on cholangiography because early histopathologic liver changes are not wellcharacterized.

Although the disease is well-known in the adult population with an estimated prevalence of about two to seven per $100,000^{(24,27)}$, its true incidence in pediatric patient population, i.e. patients in their first two decades of life, in not accurately known ${ }^{(8)}$.

Awareness of PSC in children and adolescents has only more recently increased due to better recognition of clinical and pathological manifestations as well as the more wide-spread use of invasive diagnostic techniques, i.e. endoscopic retrograde cholangio-pancreatography (ERCP) and percutaneous transhepatic cholangiography (PTC) as well as magnetic retrograde cholangiopancreatography $(\mathrm{MRCP})^{(7,12)}$.

In the adult population, multifocal strictures of the intrahepatic and extrahepatic bile ducts are characteristic ${ }^{(22)}$ and the same cholangiographic findings have been reported in pediatric patients ${ }^{(8,10,16,28)}$.
Again, in the adult population, cholangiography is considered the gold standard ${ }^{(3)}$. However, due to the equivocal clinical and pathologic picture of very early PSC in children and adolescents, the diagnostic gold standard is currently not known for that specific patient population.

Furthermore, systematic investigation of early histopathologic findings have never been undertaken. Additionally, the earliest time of occurrence and the distinct spatial location of the typical mixed inflammatory infiltrate have never been described, i.e. whether it first occurs within the biliary epithelium or in the surrounding portal tracts. How the infiltrate progresses over the course of the disease, i.e. from the bile duct wall into the portal tract or vice versa, is also not known.

Therefore, the purpose of this study was not only to report over 13 years of experience with PSC at the Children's Hospital Boston but even more to examine early pathologic manifestations and, especially, the first spatial localization of the mixed inflammatory infiltrate and its progression within the portal tract. Also, we looked at the temporal relationship between cholangiography and liver biopsy specimens, and possible associations with previous, concomitant, or subsequent diseases, e.g. autoimmune hepatitis (AlH) and inflammatory bowel disease (IBD).

\section{Methods}

\section{Patient population}

Clinical data as well as the results of imaging and pathologic examination were taken from the pertinent medical records of the hospital archives as well as from clinical information received at time of consultation.

We reviewed age, gender, clinical history, histopathology, ERCP and/or MRCP studies, and histopathology. In cases of associated IBD, gastrointestinal biopsy results were re-examined.

Other potential liver diseases, such as viral hepatitides, alcohol-induced liver damage, metabolic/ hereditary entities, immunodeficiency syndromes, and Langerhans cell histiocytosis, were excluded either at the time of first presentation or subsequently during follow-up. In cases sent in for consultation, the submitting institution was contacted for clarification purposes if necessary. 


\section{Imaging studies}

All ERCP and/or MRCP images were performed at our institution and interpreted by radiologists with expertise in biliary tree imaging. A clinicopathological correlation was subsequently undertaken.

Results of liver biopsy specimens and cholangiography were timely correlated to one another in an attempt to further define the temporal correlation between histopathology specimen and cholangiography.

\section{Pathology}

All liver biopsy specimens at our institution as well as all specimens seen in consultation were reviewed by a single hepatopathologist to ensure consistency in interpretation of the histopathologic findings. Liver biopsy specimens were routinely stained with Hematoxylin-Eosin, Masson's Trichrome, Grocotts Methenamine Silver (GMS) stain, and Periodic Acid Schiff (PAS) stain with and without diastase enzymatic digestion. Iron staining was also performed. For consultation cases, we reviewed the original material from the submitting institution and in cases of equivocal findings, requested additional unstained sections to complete our routine panel of histologic sections.

The hepatic lesions were analyzed for portal and periductal inflammation, fibro-obliterative pericholangitis ("onion-skinning"), ductopenia, ductular proliferation, periportal fibrosis with possible bridging and cirrhosis, cholestasis, steatosis, interface hepatitis, necroinflammatory activity with collapse and rosetting of hepatocytes. The severity of histopathologic findings was categorized in minimal $(1+)$, mild $(2+)$, moderate (3+), and marked (4+).

In addition, liver specimens were evaluated for possible iron deposition to exclude hereditary hemochromatosis or secondary forms of iron deposition, idiopathic or secondary cholestasis, and any significant plasma cell infiltration of portal tracts or bile ducts, indicative of concomitant autoimmune hepatitis (overlap syndrome).

In the appropriate clinical setting (i.e. no evidence of ascending cholangitis, fever, sepsis), the following histopathologic changes occurring in the background of chronic hepatitis (i.e. lymphocytic portal tract inflammation associated with mild increase in portal tract fibrosis) were interpreted as most consistent with or diagnostic of PSC:

- active mixed lymphocytic/neutrophilic cholangitis;

- moderate neutrophilic pericholangitis;

- dystrophic changes of bile ducts with mild inflammation and sclerosis;

- concentric periductal fibrosis ("onion-skinning").

\section{Results}

Our patient population consisted of a total 47 children and adolescents (35 males, 12 females) who were diagnosed with PSC at Children's Hospital in the time frame from January 1992 to April 2005. Age at diagnosis ranged from 1.5 to 20 years (mean 13 years). Of those patients, $43(91.5 \%)$ had undergone liver biopsy; $33 / 43$ patients (76.7\%) had received cholangiography as part of their diagnostic workup. Four of 47 patients were felt to have insufficient information for the diagnosis of PSC based on clinical grounds as well as lack of characteristic findings on imaging studies and, consecutively, did not have a liver biopsy performed.

Table 1 summarizes patients' gender, age at time of the liver biopsy and/or cholangiogram, liver histology results, and possible concomitant IBD and/or AlH.

All 43 patients ( 31 males, 12 females) had diagnostic findings consistent with PSC. All patients had variably intense active mixed lymphocytic and neutrophilic portal inflammation and mild portal tract fibrosis

Table 1 Comparison of patients' age and results of liver Bx and CG

\begin{tabular}{cccccccc}
\hline Patient (gender) & Result Bx & Age@Bx & Result CG & Age@CG & IBD & Age@IBD & AlH \\
E. C. (M) & Yes & 11.90 & $\mathrm{~N}$ & 11.95 & CD & 13.04 & No \\
S. B. (M) & Yes & 9.76 & $\mathrm{~N}$ & 9.74 & UC & 9.69 & No \\
J. C. M) & Yes & 4.10 & $\mathrm{~A}$ & 4.10 & UC & 3.46 & No \\
J. W. (F) & Yes & 11.47 & $\mathrm{~A}$ & 11.47 & ID & 4.92 & Yes \\
D. W. (F) & Yes & 15.25 & $\mathrm{~A}$ & 15.25 & UC & 14.62 & No \\
S. O. (M) & Yes & 6.96 & $\mathrm{~N}$ & 6.98 & UC & 7.11 & No \\
A. D. (F) & Yes & 20.81 & $\mathrm{~A}$ & 20.06 & CD & 14.49 & No \\
\hline
\end{tabular}




\begin{tabular}{|c|c|c|c|c|c|c|c|}
\hline Patient (gender) & Result Bx & Age@Bx & Result CG & Age@CG & $\mathrm{IBD}$ & Age@IBD & $\mathrm{AlH}$ \\
\hline J. S. (M) & Yes & 11.70 & A & 13.11 & ID & 11.01 & No \\
\hline D. C. (M) & Yes & 4.49 & A & 4.49 & UC & 4.40 & No \\
\hline A. S. (F) & Yes & 7.72 & $\mathrm{~N}$ & 7.77 & UC & 7.77 & No \\
\hline K. H. (M) & Yes & 16.08 & A & 16.32 & UC & 17.25 & No \\
\hline J. A. (M) & Yes & 10.41 & $\mathrm{~N}$ & 10.35 & $C D$ & 12.02 & No \\
\hline J. B. (M) & Yes & 15.48 & A & 15.57 & UC & 15.57 & No \\
\hline N. R. (M) & Yes & 16.65 & A & 16.46 & UC & 16.09 & Yes \\
\hline J. L. (M) & Yes & 14.80 & A & 14.70 & UC & 14.90 & No \\
\hline M. M. (M) & Yes & 17.1 & A & 16.11 & No & $\mathrm{N} / \mathrm{A}$ & No \\
\hline L. S. (F) & Yes & 10.11 & $\mathrm{~N}$ & 11.1 & $C D$ & 8.70 & No \\
\hline J. B. (M) & Yes & 8.8 & A & 8.8 & UC & 6 & Yes \\
\hline F. T. (M) & Yes & 13.7 & A & 13.7 & $C D$ & 11.11 & No \\
\hline M. G. (M) & Yes & $\mathrm{N} / \mathrm{E}$ & A & 12 & UC & 12.00 & No \\
\hline C. F. (M) & Yes & 12.11 & A & 13.1 & UC & 12.11 & Yes \\
\hline M. T. (M) & Yes & 16.3 & A & 16.4 & No & $\mathrm{N} / \mathrm{A}$ & Yes \\
\hline K. M. (F) & Yes & 14.4 & A & 14.4 & $\mathrm{~N} / \mathrm{E}$ & $\mathrm{N} / \mathrm{A}$ & No \\
\hline J. L. (F) & Yes & 6.2 & $\mathrm{~N} / \mathrm{E}$ & $\mathrm{N} / \mathrm{E}$ & No & $\mathrm{N} / \mathrm{A}$ & No \\
\hline S. H. (F) & Yes & 9.9 & $\mathrm{~N}$ & 10.4 & UC & 9.9 & Yes \\
\hline B. D. (F) & Yes & 14.2 & $N / E$ & $N / E$ & No & $\mathrm{N} / \mathrm{A}$ & Yes \\
\hline G. S. (F) & Yes & 13.1 & $N / E$ & $N / E$ & $\mathrm{~N} / \mathrm{E}$ & NO & No \\
\hline R. V. (M) & Yes & 14.2 & A & N/E & $N / E$ & N/A & No \\
\hline Z. D. (F) & Yes & 1.5 & $\mathrm{~N} / \mathrm{E}$ & $\mathrm{N} / \mathrm{E}$ & $\mathrm{N} / \mathrm{E}$ & $\mathrm{N} / \mathrm{A}$ & No \\
\hline D. L. (M) & Yes & 12.3 & $\mathrm{~N}$ & 12.6 & $U C$ & 11.11 & No \\
\hline J. K. (M) & Yes & 11.7 & $\mathrm{~N} / \mathrm{E}$ & $N / E$ & UC & 11.7 & No \\
\hline J. B. (M) & Yes & 8.1 & $A$ & 8.1 & $U C$ & 5.0 & Yes \\
\hline J. L. (M) & Yes & 11.0 & $\mathrm{~N} / \mathrm{E}$ & $N / E$ & $U C$ & 10.6 & No \\
\hline G. D. (M) & Yes & 19.8 & A & 19.8 & $C D$ & 13.0 & No \\
\hline M. H. (M) & Yes & 11.4 & $\mathrm{~N} / \mathrm{E}$ & N/E & UC & $<11.4$ & No \\
\hline C. G. (M) & Yes & 5.3 & $N / E$ & $N / E$ & No & N/A & No \\
\hline A. S. (M) & Yes & 3.6 & $\mathrm{~N} / \mathrm{E}$ & $\mathrm{N} / \mathrm{E}$ & No & $\mathrm{N} / \mathrm{A}$ & No \\
\hline M. S. (M) & Yes & 14.11 & $\mathrm{~N} / \mathrm{E}$ & $\mathrm{N} / \mathrm{E}$ & $C D$ & 12.0 & No \\
\hline K. O. (M) & Yes & $18.0^{*}$ & $\mathrm{~N}$ & 18.1 & No & $N / A$ & No \\
\hline D. R. (M) & Yes & 12.0 & A & 15.3 & UC & 15.3 & Yes \\
\hline K. T. (M) & Yes & 11.0 & A & 11.0 & UC & 11.0 & Yes \\
\hline A. A. (F) & Yes & 15.9 & A & 15.10 & $C D$ & 15.1 & No \\
\hline M. Y. (M) & Yes & 15.5 & $A$ & 15.5 & $U C$ & 16.5 & Yes \\
\hline J. R. (M) & N/E & $\mathrm{N} / \mathrm{E}$ & $\mathrm{A} / \mathrm{N \#}$ & 11.6 & UC & 11.0 & No \\
\hline D. P. (M) & $\mathrm{N} / \mathrm{E}$ & $\mathrm{N} / \mathrm{E}$ & A & 14.8 & UC & 13.8 & No \\
\hline G. F. (M) & $\mathrm{N} / \mathrm{E}$ & $\mathrm{N} / \mathrm{E}$ & $A$ & 10.10 & $U C$ & 9.4 & No \\
\hline J. G. (M) & $\mathrm{N} / \mathrm{E}$ & $\mathrm{N} / \mathrm{E}$ & A & 14.0 & UC & 13.7 & No \\
\hline
\end{tabular}

Bx: biopsy; CG: cholangiogram; IBD: inflammatory bowel disease; AlH: autoimmune hepatitis; M: male; F: female; N: normal; A: abnormal; CD: Crohn disease; UC: ulcerative colitis; ID: indeterminate colitis; N/E: not examined/no information available; N/A: not applicable; *: exact time of first diagnosis not known; \#: result unclear; two magnetic retrograde cholangiopancreatography (MRCP) exams with conflicting results.

Note: Numbers equal age in years and months (xx.yy). 
(Figures 1A and 3A). The inflammatory infiltrate was mainly composed of lymphocytes and monocytes with some interspersed eosinophilic and neutrophilic granulocytes.

Of those 43 patients with diagnostic liver pathology, 33 (25 males, eight females) patients also had a cholangiogram performed at some point during their evaluation; 24 of those 33 (72.7\%; 19 males, five females) showed an abnormal cholangiogram and nine patients (24.2\%; six males, three females) had normal cholangiographic results. Finally, 10/43 patients (six males, four females) had no cholangiography done.

About half of the patients $(11 / 24)$ (eight males, three females) who were found with abnormal liver histology presented with abnormal imaging findings at the same time. The same number $(11 / 24)$ of patients (nine males, two females) had abnormal findings on liver histology and cholangiography at different points in time. Of those 11 patients, seven individuals (63.6\%) (six males, one female) were noticed with abnormal liver histology before typical findings on cholangiography were visualized. In four (36.4\%) patients (three males, one female), the situation was vice versa, i.e. abnormal cholangiogram before abnormal liver histology. Available data of 2/24 patients were insufficient for correlation purposes.

Active $(>1+)$ mixed lymphocytic/neutrophilic cholangitis was seen in 19 (44.2\%) patients (14 males, five females) (Figures 1B, 2C, 2E and 2F), moderate (3+) to marked (4+) neutrophilic pericholangitis in nine (20.9\%) patients (six males, three females) (Figures 1C, 1D and 2D), and mild $(1+)$ inflammation and sclerosis with dystrophic changes of bile ducts in eight (18.6\%) patients (seven males, one female) (Figures 2A and 2B).

Characteristic concentric ("onion-skinning") periductal fibrosis was noted in $24(55.8 \%)$ patients (17 males, seven female) (Figures 3E and 3F). Of that group, one patient (J. B.) revealed an extremely severe degree of "onionskinning", which prevented further evaluation of bile ducts regarding the possible presence of an inflammatory component. All other 23 patients were distributed among the previously categorized groups.

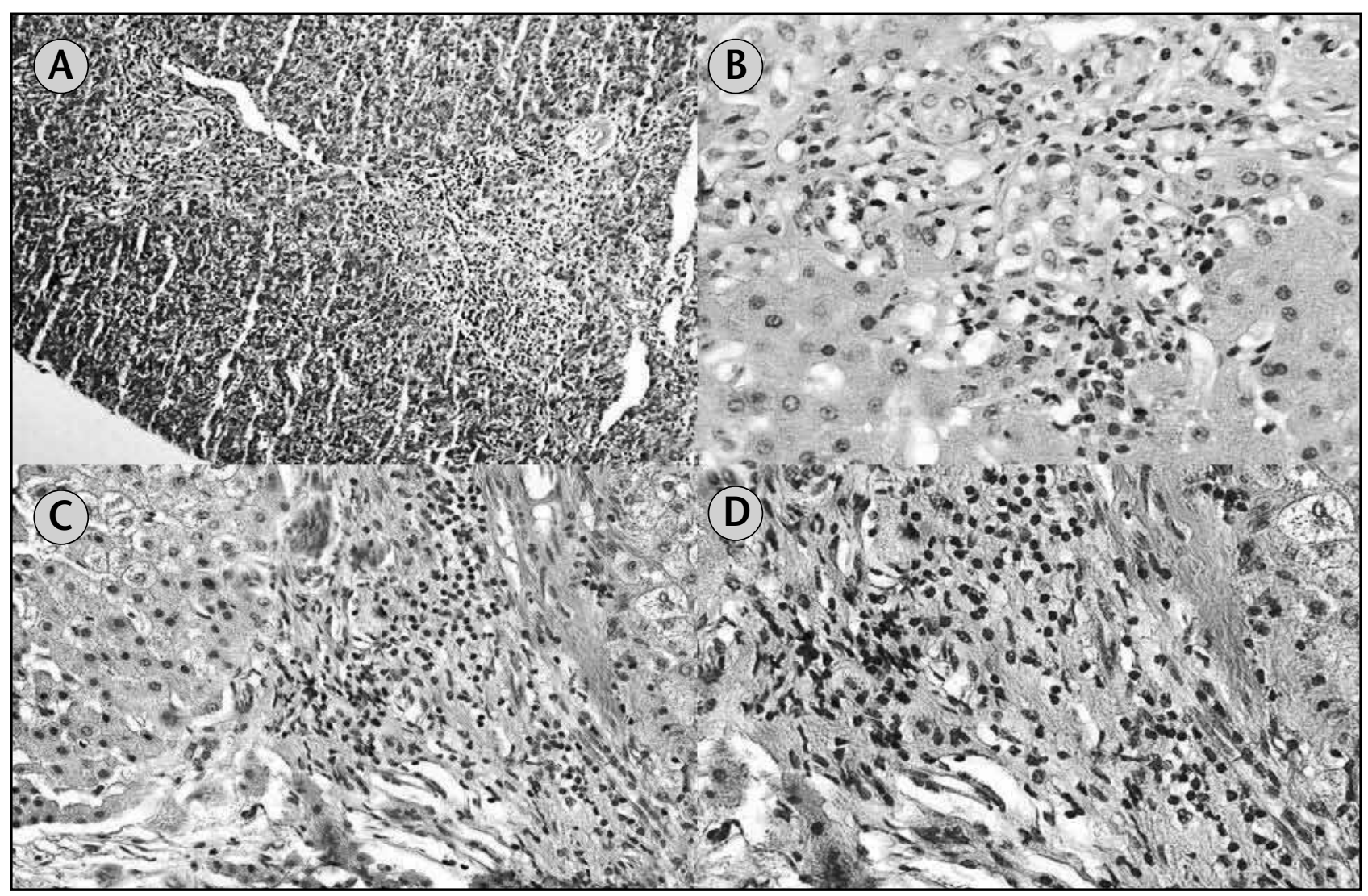

Figura 1 - Photomicrograph of different PT. (A) Medium power view of two PT with mild active mixed lymphocytic and neutrophilic inflammation surrounding and involving bile ducts (20x); (B) high power view of PT with moderate mixed inflammation (40x); (C) medium power view of PT showing marked mixed inflammatory infiltrate (20x); (D) high power view of the same PT ("C") demonstrating marked bile duct wall involvement by mixed inflammation as well as destruction of some bile ducts (60x)

PT: portal tracts. 


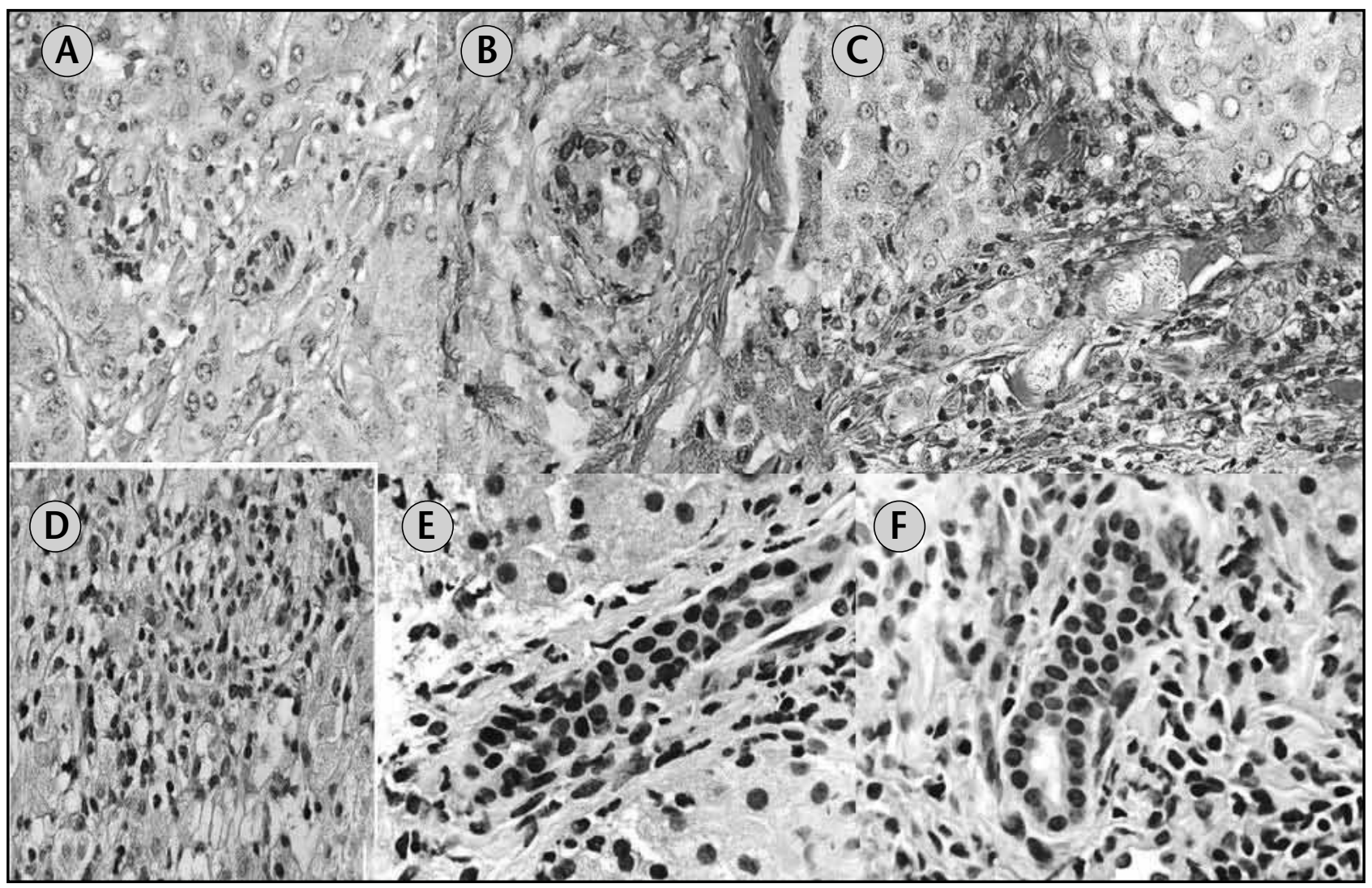

Figura 2 - Photomicrographs of different BD. (A and B) Medium and high power views of BD showing dystrophic changes of bile ducts with mild inflammation and sclerosis (20x and 40x); (C) medium power view of PT with BD proliferation and marked mixed inflammation (20x); (D) medium power view of BD with marked neutrophilic pericholangitis (20x); ( $E$ and $F)$ high power views of $B D$ with minimal (early) neutrophilic pericholangitis (60x)

$B D$ : bile ducts.

Of 43 patients with unequivocal histopathologic features of PSC, 31 (72.1\%; 20 males, 11 females) had more advanced disease with compression and obliteration of bile ducts and also showed extension of portal tract fibrosis (Figures 3B and $\mathbf{3 C}$ ) beyond the limiting plate $(3+)$, ultimately resulting in portal to portal bridging fibrosis (4+) (Figure 3D). End-stage liver disease due to diffuse parenchymal cirrhosis was identified in 12 patients (27.9\%; five males, seven females). Significant numbers of portal plasma cells, suggestive of concomitant autoimmune hepatitis as part of overlap syndrome, were found in 11 patients (25.6\%; eight males, three females).

Iron deposition within the liver parenchyma was solely observed in one patient. This patient, however, only had minimal scattered traces of stainable iron which was not suggestive of a disturbance in iron metabolism. Chronic cholestasis for unclear reasons was evident in one patient and two additional patients had minimal and scattered fat droplets within hepatocytes; none of the remaining patients showed cholestasis.

All detailed histopathologic liver findings as well as the grading regarding their severity are summarized in Table 2.
Coexistence of IBD was observed in 36 of 47 patients (76.6\%; 29 males, seven females), of which 26 (55.3\%; 23 males, three females) were diagnosed with ulcerative colitis, eight (17\%; five males, three females) with Crohn disease, and two (4.3\%; one male, one female) with indeterminate colitis.

Liver biopsies were performed in 32 (88.9\%) of 36 patients (25 males, seven females) with associated IBD. Regarding the temporal correlation of IBD and PSC, 15 (46.9\%) of those 32 patients (nine males, six females) presented with IBD before PSC and six (18.8\%) patients (all males) vice versa. In eight (25\%) patients (seven males, one female), both diagnoses were simultaneously obtained. For three (9.4\%) patients (two males, one female), insufficient clinical information were at hand to draw conclusions (Table 1).

\section{Discussion}

The current study describes - to the best of our knowledge - the second largest population of children and adolescents with PSC. The only study with a larger group of patients $(n=52)$ focused on the long-term follow-up and 


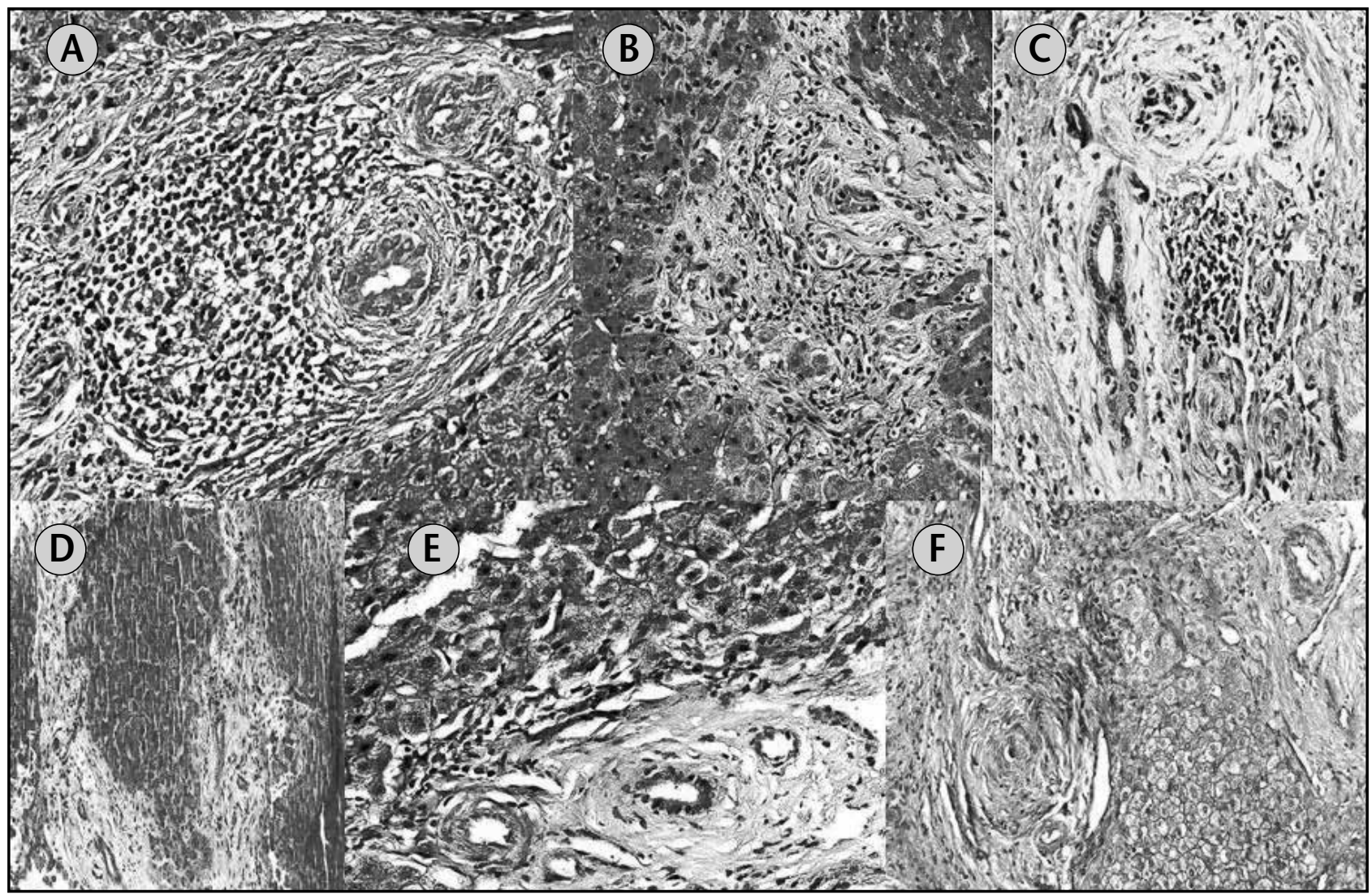

Figura 3 - Photomicrographs of different degrees of PT fibrosis. (A) High power view of PT with mild fibrosis surrounding bile ducts (40x); (B) medium power view of PT with moderate fibrosis and focal periportal extension (20x); (C) high power view of PT with marked fibrosis, compressing and obliterating some bile ducts (yellow arrowheads; 40x); (D) medium power view of two PT showing portal to portal bridging fibrosis and early cirrhosis (20x); (E and F) high and medium power views, respectively, of PT with several bile ducts demonstrating marked concentric periductal fibrosis ("onion skinning") (60x [E]; 40x [F])

PT: portal tracts.

therapeutic modalities rather than attempting a systematic evaluation of early histopathologic changes to facilitate early recognition of the disease in liver biopsy specimens ${ }^{(12)}$.

Another article ${ }^{(5)}$ also emphasized histologic followup data of 20 young PSC patients rather than evaluating early histopathologic changes and most of those patients initially presented with advanced liver disease (bridging fibrosis or cirrhosis), findings that were different from those in our patient population in which about two-thirds were diagnosed in an early stage of the disease.

PSC in the pediatric age group, i.e. 0-20 years of age, has mostly been diagnosed in the second decade of life $(5,8,10,12,13,28)$. The age range of our patient population ( $n=47)$ diagnosed at the Children's Hospital matched this observation and encompassed 35 males and 12 females, ranging in age from 5 to 24 years (mean 13 years). However, earlier presentations in patients of younger age have occasionally been observed and some patients were diagnosed below 2 years of age ${ }^{(12)}$. Interestingly, at the time of diagnosis, our youngest patient was 1.5 years old.
Most of our patients were males who were initially found to have unspecific signs and symptoms of chronic liver disease, e.g. fatigue, jaundice, abdominal pain, and hepatosplenomegaly. Those features were in concordance with findings made by other observers ${ }^{(5,8,10,12,13,28)}$.

Of those patients who had received a liver biopsy, almost half of them (19/43) were diagnosed at an early stage and showed discrete minimal to mild neutrophilic pericholangitis without evidence of cholestasis. This discovery indicated that a relatively high percentage of pediatric patients were able to present with rather mild unspecific liver histopathology, leaving a larger differential diagnosis open for further investigation. This observation consecutively highlighted the necessity of searching for possible additional clinical findings such as concomitant inflammatory bowel disease or autoimmune-hepatitis.

All our patients with minimal to mild neutrophilic pericholangitis additionally presented with minimal or mild portal tract inflammation with associated fibrosis, suggesting 
Table 2 Histopathologic features of liver biopsies in the patients population (severity of pathologic changes indicated as $1+/ 2+=\mathrm{minimal} / \mathrm{mild} ; 3+/ 4+=$ moderate $/ \mathrm{marked}$ )

\section{Patient (gender)}

E. C. (M)

S. B. (M)

J. C. (M)

J. W. (F)

D. W. $(F)$

S. 0. (M) 1-2t

A. D. (F)

J. S. (M)

D. C. (M)

A. S. (F)

K. H. (M)

PTI

BDI "Onion

$2+$

$2+$ skinning"

N/E

PTF

$2+$

BRID

No

$2+$

$2-3+$

$2+$

Yes

$2+$

$4+$

No

3-4+

Yes

$4+$

Yes

$4+$

Yes

No

$4+$

$4+$

Yes

$4+$

Yes

J. A. (M)

$2+$

$2+$

$2+$

Yes

$2+$

$4+$

Yes

$3+$

$4+$

$2+$

J. B. (M)

$1-2+$

$1+$

Yes

N. R. (M) 3-4+

J. L. (M)

$3+$

M. M. (M) 3+

L. S. (F) 3+

J. B. (M) 2+

F. T. (M)

$2+$

M. G. (M)

$2+$

C. F. (M)

$3+$

M. T. (M)

$2+$

K. M. (F) 3+

J. L. (F) 3+

S. H. (F) 2+

B. D. (F) 2+

G. S. (F) 2+

R. V. (M) 1+

Z. D. (F) 2+

D. L. (M)

$2+$

J. K. (M)

$2+$

$3+$

$4+$

3-4+

$3+$

$2+$

$2+$

$2+$

$2+$

3-4+

$2+$

$3+$

N/A\#

$2+$

$4+$

$1+$

Yes

Yes

$4+$

3-4+

Yes

No

3-4+

No

$2+$

Yes

$4+$

No

$2+$

Yes

$2+$

3-4+

$4+$

$3+$

$4+$

$4+$

$3+$

Yes

Yes

$4+$

No

$2+$

$3+$

$3+$

$4+$

$3+$

4+ Yes

J. L. (M)

$2+$

$2+$

$2+$

Yes

$1+$

No

$2+$

$3+$

Yes

No

No

No

Yes

No

M. H. (M)

CIRR

No

No

Yes

Yes

Yes

$Y$ es

No

No

No

Yes

No

No

No

No

No

No

No

Yes

No

No

No

No

No

Yes

No

No

Yes

No

Yes

No

No

No

No

No

No

LNIA

N/E

PC

CS FE

No No No

$2+$

No

No No

$1+$

No

No No

2-3+

Yes

No

$1-2+$

No

Yes

$1+$

N/E

$1+$

No

No No

N/E

No

$2+$

No

No No

2+

re

\begin{abstract}
(2)
\end{abstract}

$\mathrm{N} / \mathrm{E}$

No

No No

$1+$

$1-2+$

No

No No

N/E

3-4+

2-3+

No

No No

No

No No 


\begin{tabular}{lcccccccccc}
\hline $\begin{array}{c}\text { Patient } \\
\text { (gender) }\end{array}$ & PTI & BDI & $\begin{array}{c}\text { "Onion } \\
\text { skinning" }\end{array}$ & PTF & BRID & CIRR & LNIA & PC & CS & FE \\
C. G. (M) & $2+$ & $2+$ & No & $4+$ & Yes & No & $2+$ & No & No & No \\
A. S. (M) & $1+$ & $1+$ & No & $4+$ & Yes & Yes & No & No & No & No \\
M. S. (M) & $2+$ & $1+$ & Yes & $2+$ & No & No & No & No & No & No \\
K. O. (M) & $2+$ & $2+$ & NO & $3-4+$ & Yes & No & No & No & No & No \\
D. R. (M) & $2-3+$ & $2-3+$ & No & $4+$ & Yes & Yes & $1+$ & Yes & No & No \\
K. T. (M) & N/E & N/E & N/E & N/E & N/E & N/E & N/E & Yes & N/E & No \\
A. A. (F) & $2+$ & N/E & N/E & $4+$ & Yes & Yes & No & No & No & No \\
M. Y. (M) & N/E & N/E & N/E & N/E & N/E & N/E & N/E & Yes & N/E & N/E \\
\hline
\end{tabular}

PTI: portal tract inflammation; BDI: bile duct inflammation (pericholangitis); PTF: portal tract fibrosis; BRID: bridging fibrosis; CIRR: cirrhosis; LNIA: Iobular necroinflammatory activity; PC: plasmacells; CS: cholestasis; FE: iron deposition; N/E: not evaluated/no results available for review; N/A: not applicable; \&: bile duct proliferation; \%: degree of bile duct sclerosis obscured definitive evaluation of associated pericholangitis; \#: atrophy.

\section{Grading of BDI:}

$=1+$ interpreted as mild cholangitis and sclerosis with dystrophic BD changes;

$=>1+$ interpreted as active mixed lymphocytic/neutrophilic cholangitis;

$=>2+$ interpreted as moderate to marked neutrophilic pericholangitis.

that the earliest histopathologic manifestation of PSC might be seen within the bile duct wall. However, variably intense chronic inflammation of the portal tracts was observed in all patients, rendering this specific finding not very reliable for diagnostic differentiation of PSC from other etiologies like immune-mediated or viral causes. Therefore, additional diagnostic tools, such as imaging studies and information about the clinical history, were necessary for finally sorting out the underlying disease process.

Batres et al. showed in their study that most patients $(13 / 20)$ initially presented with advanced disease ${ }^{(5)}$. Interestingly, most of them also demonstrated a discrete neutrophilic cholangitis without significant tissue cholestasis. In addition, there was ductal/ductular proliferation noted, suggesting that neutrophilic cholangitis - due to its continuous presence in later disease stages - may be a major diagnostic clue in early disease.

Ductal/ductular proliferation was not very obvious in our patients, leading to further speculation that discrete neutrophilic cholangitis may be one of the earliest - if not the earliest - histopathologic finding of PSC.

Interestingly, Feldstein et al. found that only $20 \%$ of their patients had periductal inflammation, $30 \%$ periductal fibrosis, and $30 \%$ fibro-obliterative cholangitis ${ }^{(12)}$. This lower percentage might be explained by a different patient population at that institution. That medical center has been known to function as major referral center for PSC patients, possibly resulting in application of a different clinical threshold for performing an initial liver biopsy.

Previous studies $^{(8,10,12,13,28)}$ did not comment on the temporal correlation between abnormal liver biopsy and cholangiogram. Therefore, our study was the first attempting to correlate those data. We found that of those 24 patients with an abnormal cholangiogram, i.e. beading of intrahepatic bile ducts and/or dilation of intra or extrahepatic bile ducts, 11 (eight males, three females) were found with abnormal liver histology and abnormal imaging findings at the same time.

The same number $(11 / 24)$ of patients (nine males, two females) had abnormal findings on liver histology and cholangiography at different points in time. Of those 11 patients, seven (six males, one female) were noticed with abnormal liver histology before typical findings on cholangiography were visualized. In 4/11 patients (three males, one female), the situation was vice versa, i.e. abnormal cholangiogram before abnormal liver histology. Available data of $2 / 24$ patients were insufficient for correlation purposes.

Association of PSC with AlH has been well known in the literature ${ }^{(6,9,14,18)}$. Prior studies suggested that PSC in children and adolescents might even mimic $\mathrm{AlH}$ because many patients were initially found to have high 
immunoglobulin serum levels, circulating autoantibodies, and interface hepatitis on liver biopsy $(10,13,16,28,21)$.

Concomitant occurrence of PSC and $\mathrm{AlH}$ (overlap syndrome) has been described with variable prevalence $^{(12,28)}$. Rapid progression of autoimmune hepatitis in the background of PSC has been observed as well(17). Generally, percentages of overlap syndrome in children and adolescents are substantially greater than those in adults, i.e. $7.1 \%$ to $10.6 \%{ }^{(1,19,26)}$. In our study, $11(25.6 \%)$ of our patients (eight males, three females) harbored significant numbers of plasma cells in their liver biopsy specimens, suggesting the possibility of concomitant AlH.

High association of concurrent PSC and IBD, mostly ulcerative colitis, in the adult population has been documented in the literature ${ }^{(20)}$, ranging from $53 \%{ }^{(28)}$ to up to $98 \%{ }^{(29)}$. In the pediatric age group, this association has been much less frequently identified ${ }^{(11,25)}$.

We observed concurrent PSC and IBD in 36 (76.6\%) of our patients ( 29 males, seven females) and the percentage of IBD in our cohort was within the range of prior studies $^{(12,25,28)}$. Of those 36 patients, 23 males and three females (72.2\%) were diagnosed with ulcerative colitis, five males and three females (22.2\%) with Crohns disease, and one male and one female (5.6\%) with indeterminate colitis.

Although an autoimmune etiology for both PSC and IBD has been favored ${ }^{(30)}$, definitive evidence for this link is still lacking and much more needs to be elucidated, especially regarding the timely correlation of IBD and PSC to one another.

In our cohort, 15 (46.9\%) patients (nine males, six females) had presented with IBD before clinical evidence of PSC was found. Of those, six patients (18.8\%; all males) were first diagnosed with PSC; in eight patients (25\%; seven males, one female) both diagnoses were simultaneously made.

Conflicting results to our observation that a higher percentage of pediatric patients were diagnosed with IBD before PSC come from the Feldstein group who pointed out the possibility of silent IBD, which would only be detectable by endoscopy at time of clinically manifested PSC. Regrettably, these studies did not comment in detail on the specific time course of both disease entities.
In summary, our study emphasized that in the appropriate clinical context, such as association with concurrent inflammatory bowel disease or autoimmune hepatitis, the diagnosis of primary sclerosing cholangitis can be made by liver biopsy alone, i.e. in the absence of cholangiographic examination or even when the cholangiogram is still unremarkable because of the early stage of disease.

Characteristic histopathologic features were chronic portal inflammation with neutrophilic pericholangitis and/or periductal sclerosis associated with "onionskinning". It should be remembered, though, that neutrophilic pericholangitis, particularly in early disease, can be subtle and, therefore, easily overlooked, especially when evaluating limited amounts of tissue. Consequently, a high level of initial suspicion for PSC by the histopathologist is recommended as well as taking into consideration other potentially associated clinical abnormalities, such as autoimmune hepatitis or inflammatory bowel disease

\section{Acknowledgement}

The authors would like to express their thanks to Antonio R. Perez-Atayde, MD, Children's Hospital, Boston, MA, USA, for reviewing the histologic slides of the cases and for some fruitful discussions while preparing this manuscript.

\section{Dedication}

This work is dedicated to the late Tucker Collins, M.D., Ph.D., former Chairman and Pathologist-in-Chief, Children's Hospital, Boston, MA, USA.

Dr. Collins unmatched leadership and deep commitment to clinical and basic science has constantly fertilized a highly stimulating intellectual environment at his department.

It is without any doubt that much scientific work would not have been completed without Dr. Collins' guidance and support. His legacy will continue to remain vividly alive in all those who were deeply influenced by him.

\section{References}

1. ALVAREZ, F. et al. International Autoimmune Hepatitis Group Report: review of criteria for diagnosis of autoimmune hepatitis. J Hepatol, v. 31, n. 5, p. 929-38, 1999.
2. ANGULO, P. et al. Medical treatment for primary sclerosing cholangitis: risk versus benefit. Hepatology, v. 32, n. 4, Pt 1, p. 871-2, 2000. 
3. ANGULO, P. et al. Primary sclerosing cholangitis. Hepatology, v. 30, n. 1, p. 325-32, 1999.

4. BARBATIS, C. et al. Histological features of sclerosing cholangitis in patients with chronic ulcerative colitis. J Clin Pathol, v. 38, n. 7, p. 778-83, 1985.

5. BATRES, L. A. et al. Primary sclerosing cholangitis in children: a histologic follow-up study. Pediatr Dev Pathol, v. 8, n. 5, p. 568-76, 2005.

6. BAYER, E. M. et al. Autoimmune liver disease: diagnosis and therapy. Z Gastroenterol, v. 42, n. 1, p. 19-30, 2004.

7. CHAVHAN, G. B. et al. Primary sclerosing cholangitis in children: utility of magnetic resonance cholangiopancreatography. Pediatr Radiol, v. 38, n. 8, p. 868-73, 2008.

8. DEBRAY, D. et al. Sclerosing cholangitis in children. J Pediatr, v. 124, n. 1, p. 49-56, 1994.

9. EBBESON, R. L. et al. Diagnosing autoimmune hepatitis in children: is the International Autoimmune Hepatitis Group scoring system useful? Clin Gastroenterol Hepatol, v. 2, n. 10, p. 935-40, 2004.

10. EL-SHABRAWI, M. et al. Primary sclerosing cholangitis in childhood. Gastroenterology, v. 92, n. 5, Pt 1, p. 1226-35, 1987.

11. FAUBION Jr, W. A. et al. Pediatric "PSC-IBD": a descriptive report of associated inflammatory bowel disease among pediatric patients with PSC. J Pediatr Gastroenterol Nutr, v. 33, n. 3, p. 296-300, 2001.

12. FELDSTEIN, A. E. et al. Primary sclerosing cholangitis in children: a long-term follow-up study. Hepatology, v. 38, n. 1, p. 210-7, 2003.

13. FLOREANI, A. Primary sclerosing cholangitis (PSC): clinical, laboratory and survival analysis in children and adults. Liver, v. 19, n. 3, p. 228-33, 1999.

14. GHEORGHE, L. et al. Frequency and predictive factors for overlap syndrome between autoimmune hepatitis and primary cholestatic liver disease. Eur J Gastroenterol Hepatol, v. 16, n. 6, p. 585-92, 2004.

15. GRAZIADEI, I. W. et al. Long-term results of patients undergoing liver transplantation for primary sclerosing cholangitis. Hepatology, v. 30, n. 5, p. 1121-7, 1999.

16. GREGORIO, G. V. et al. Autoimmune hepatitis/sclerosing cholangitis overlap syndrome in childhood: a 16-year prospective study. Hepatology, v. 33, n. 3, p. 544-53, 2001.

17. HONG-CURTIS, J. et al. Rapid progression of autoimmune hepatitis in the background of primary sclerosing cholangitis. J Clin Gastroenterol, v. 38, n. 10, p. 906-9, 2004.

18. JOO, M. et al. Pathologic features of ulcerative colitis in patients with primary sclerosing cholangitis: a casecontrol study. Am J Surg Pathol, v. 33, n. 6, p. 854-62, 2009.

19. KAYA, M. et al. Overlap of autoimmune hepatitis and primary sclerosing cholangitis: an evaluation of a modified scoring system. J Hepatol, v. 33, n. 4, p. 537-42, 2000.

20. KNIGHT, C. et al. Hepatobiliary associations with inflammatory bowel disease. Expert Rev Gastroenterol Hepatol, v. 3, n. 6, p. 681-91, 2009.

21. KOYABU, M. et al. Analysis of regulatory $T$ cells and IgG4-positive plasma cells among patients of IgG4- related sclerosing cholangitis and autoimmune liver diseases. J Gastroenterol, 2010. [Epub 2010 Jan 20]

22. MACCARTY, R. L. et al. Primary sclerosing cholangitis: findings on cholangiography and pancreatography. Radiology, v. 149, n. 1, p. 39-44, 1983.

23. MAGGS, J. R. et al. An update on primary sclerosing cholangitis. Curr Opin Gastroenterol, v. 24, n. 3, p. 377-83, 2008. [Review]

24. OLSSON, R. G. et al. Prognostic value of cholangiography in primary sclerosing cholangitis. Eur J Gastroenterol Hepatol, v. 7, n. 3, p. 251-4, 1995.

25. ROBERTS, E. A. Primary sclerosing cholangitis in children. J Gastroenterol Hepatol, v. 14, n. 6, p. 588-93, 1999. [Review]

26. VAN BUUREN, H. R. et al. High prevalence of autoimmune hepatitis among patients with primary sclerosing cholangitis. J Hepatol, v. 33, n. 4, p. 543-8, 2000.

27. WIESNER, R. H. Current concepts in primary sclerosing cholangitis. Mayo Clin Proc, v. 69, n. 10, p. 969-82, 1994. [Review]

28. WILSCHANSKI, M. et al. Primary sclerosing cholangitis in 32 children: clinical, laboratory, and radiographic features, with survival analysis. Hepatology, v. 22, n. 5, p.1415-22, 1995.

29. WOODWARD, J. et al. Autoimmune overlap syndromes. Hepatology, v. 33, n. 4, p. 994-1002, 2001. [Review]

30. YANG, $X$. et al. Susceptibility to primary sclerosing cholangitis is associated with polymorphisms of intercellular adhesion molecule-1. J Hepatol, v. 40, n. 3, p. 375-9, 2004.
Mailing address

Wolfram F. . Riedlinger Department of Pathology Aberdeen University Medical School Aberdeen Royal Infirmary Foresterhill Aberdeen AB25 9ZD United Kingdom Phone: +44-1224-552852 Fax: +44-1224-663002 e-mail: w_riedlinger@yahoo.de 